\title{
IMPLEMENTASI PROGRAM STUDEPRENEUR SEBAGAI UPAYA MENCIPTAKAN WIRAUSAHA BARU DAN MODEL PENGEMBANGAN KEWIRAUSAHAAN PERGURUAN TINGGI
}

Dito Rinaldo *

Sekolah Tinggi Ilmu Ekonomi Ekuitas Bandung

Mirza Hedismarlina Yuneline Sekolah Tinggi Ilmu Ekonomi Ekuitas Bandung

\section{Ivan Diryana}

Sekolah Tinggi Ilmu Ekonomi Ekuitas Bandung

\begin{abstract}
IMPLEMENTATION OF STUDEPRENEUR PROGRAM AS AN EFFORTS IN CREATING NEW ENTREPRENEURS AND THE ENTREPRENEURSHIP DEVELOPMENT MODEL FOR HIGHER EDUCATION. This Community Service Program is related to the implementation of the Studepreneur program, which is a business incubator program in STIE Ekuitas. Studepreneur program is available to strengthen the business that run by students, either obtained from STIE Ekuitas and outside its. The Studepreneur program is implemented within 1 (one) year. In the implementation of the program, STIE Ekuitas team of community service program collaborate with various parties such as Kadin, financial institutions, BPOM and other parties. The Parties involved directly in the implementation of 7 (seven) levels of Studepreneur, either as trainer, consultant, resource person or assistant. The STIE Ekuitas team creates a model of entrepreneurship development, which is expected to be a reference in the entrepreneurship development program at STIE Ekuitas and other universities. The entrepreneurship development model of STIE Ekuitas is based on the experience and evaluation results of the Studepreneur program period 2016-2017, and will be implemented in the entrepreneurship development program in period 2017-2018. In addition this community service program create 13 new entrepreneurs.
\end{abstract}

* Corresponding Author: Sekolah Tinggi Ilmu Ekonomi Ekuitas; Buana Soetta Residence Blok D2 No. 7 Gedebage Bandung 40294; Email: rinaldo.dito09@gmail.com

Article History: Received: 10-10-2017; Revised: 10-11-2017; Accepted: 28-11-2017

Permalink: http://ppm.ejournal.id/index.php/pengabdian/article/view/25

How to cite (APA): Rinaldo, D., Yuneline, M. H., \& Diryana I. (2017). Implementasi program Studepreneur sebagai upaya menciptakan wirausaha baru dan model pengembangan kewirausahaan perguruan tinggi. Jurnal Pengabdian Pada Masyarakat, 2(2), 127-134.

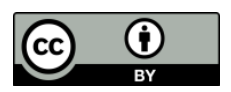

This is an open access article distributed under the terms of the Creative Commons Attribution 4.0 International License, which permits unrestricted use, distribution, and reproduction in any medium, provided the original work is properly cited. @ 2017, Dito Rinaldo, Mirza Hedismarlina Yuneline, Ivan Diryana.

\section{PENDAHULUAN}

Jumlah UMKM di Indonesia sejak 2005 sampai dengan 2013 terus mengalami pertumbuhan (BPS, 2016). Jumlah UMKM yang semakin banyak merupakan hal yang positif, mengingat dengan bertambahnya jumlah UMKM dapat mendorong pergerakan ekonomi ke arah yang lebih baik. Bertambahnya jumlah UMKM dapat mengurangi permasalahan pengangguran di Indonesia, 
meningkatkan daya beli masyarakat, meningkatkan pendapatan nasional, ekspor dan lain sebagainya.

Tabel 1. Data UMKM 2007-2013

\begin{tabular}{|c|c|c|c|c|c|c|c|c|}
\hline No. & Indikator & 2007 & 2008 & 2009 & 2010 & 2011 & 2012 & 2013 \\
\hline 1 & Jumlah UMKM & 50145800 & 51409612 & 52764603 & 53823732 & 55206444 & 56534592 & 57895721 \\
\hline 2 & Pertumbuhan Jumlah UMKM & 2.29 & 2.52 & 2.64 & 2.01 & 2.57 & 2.41 & 2.41 \\
\hline 3 & Jumlah Tenaga Kerja UMKM & 90491930 & 94024278 & 96211332 & 99401775 & 101722458 & 107657509 & 114144082 \\
\hline 4 & Pertumbuhan Jumlah Tenaga Kerja UMKM & 2.94 & 3.90 & 2.33 & 3.32 & 2.33 & 5.83 & 6.03 \\
\hline 5 & Sumbangan PDB UMKM (harga konstan) & 1099301.10 & 1165753.20 & 1212599.30 & 1282571.80 & 1369326.00 & 1451460.20 & 1536918.80 \\
\hline 6 & Pertumbuhan sumbangan PDB UMKM & 6.46 & 6.04 & 4.02 & 5.77 & 6.76 & 6.00 & 5.89 \\
\hline 7 & Nilai Ekspor UMKM & 140363.84 & 178008.28 & 162254.52 & 175894.89 & 187441.82 & 166626.50 & 182112.70 \\
\hline 8 & Pertumbuhan Nilai Ekspor UMKM & 13.41 & 26.82 & -8.85 & 8.41 & 6.56 & -11.10 & 9.29 \\
\hline
\end{tabular}

Sumber: Badan Pusat Statistik (2016)

Berdasarkan data pada Tabel 1, jumlah UMKM terus meningkat, bahkan di masa krisis 2008 pertumbuhan UMKM masih positif, hal ini menunjukan bahwa tingkat ketahanan umkm diperiode krisis cukup baik. Penyerapan tenaga kerja oleh UMKM pun terus bertambah, di tahun 2007 jumlah tenaga kerja UMKM sebanyak 90.491 .930 orang meningkat menjadi 114.144 .082 orang di tahun 2013. Nilai ekspor UMKM semakin tinggi, tercatat pada tahun 2013 pertumbuhan nilai ekspor sebesar $9.29 \%$. Beberapa penelitian juga menunjukan bagaimana dampak positif keberadaan UMKM bagi pertumbuhan ekonomi Indonesia, salah satunya adalah penelitian Supriyanto (Suci, 2017) menyimpulkan bahwa UMKM mampu menjadi solusi penanggulangan kemiskinan di Indonesia, karena ternyata sektor UMKM memiliki kontribusi yang besar dalam penyerapan tenaga kerja, yaitu menyerap lebih dari 99,45\% tenaga kerja dan sumbangan terhadap PDB sekitar 30\%.

Perkembangan UMKM yang sedemikian pesat tidak lepas dari permasalahan-permasalahan, yang dapat menjadi pemicu runtuhnya UMKM dimasa yang akan datang. Ardiana et al (2010) memaparkan bahwa dari 140 responden pengusaha UMKM 2008 di Surabaya, memiliki beraneka latar belakang taraf pendidikan yaitu Sekolah Dasar berjumlah 21 orang, dan Sekolah Lanjutan Tingkat Pertama sebanyak 17 orang serta Sekolah Menengah Umum berjumlah 72 orang. Dari paparan data penelitian tersebut disimpulkan bahwa sebanyak $73 \%$ pengusaha UMKM berlatar belakang pendidikan di bawah S1, dengan sebaran umur yang relatif muda, yaitu $<25$ tahun sejumlah 22 orang, pengusaha berumur 25 sampai dengan 30 tahun berjumlah 25, dan umur 30,01 sampai 35 tahun berjumlah 32 orang, dan umur 35,01 sampai dengan 40 tahun berjumlah 23 orang, pada aspek pengelolaan lama usaha disebutkan berkisar 10-20 tahun sejumlah 36\%. Maka dapat disimpulkan dalam pengelolaan UMKM terdapat keterbatasan manajerial. Adanya keterbatasan ini menyebabkan tatakelola bisnis UMKM sangat 
rendah. Tatakelola bisnis (Good Corporate Governance) yang buruk ini menjadi penyebab pendeknya keberlangsungan bisnis UMKM. Contoh kasus, Hanifah (2015) menyebut bahwa penerapan tatakelola bisnis di 35 UMKM di wilayah Bandung masih memerlukan banyak perbaikan terutama karena lemahnya transparansi dan akuntabilitas.

Untuk menanggulangi permasalahan tersebut maka diperlukan peran berbagai pihak, guna membantu kemandirian UMKM.Pemerintah, swasta, praktisi dan akademisi perlu melakukan kolaborasi untuk menyusun program-program yang efektif dalam pembentukan wirausaha baru yang mandiri. Peran perguruan tinggi dalam menciptakan wirausaha yang berdaya saing sangat dibutuhkan, salah satunya melalui program inkubator bisnis (Pinayani, 2006, p. 6). STIE Ekuitas sebagai lembaga pendidikan juga mendukung program pengembangan kewirausahaan, salah satunya melalui program Studepreneur. Dalam program pengabdian ini, diupayakan evaluasi secara berkesinambungan, sehingga ditemukan model yang tepat bagi pengembangan kewirausahaan khususnya bagi mahasiswa wirausaha.

\section{METODE PELAKSANAAN}

Dalam pelaksanaan pengabdian ini mengadopsi konsep Deming: Plan-DoCheck-Act (PDCA) sebagai metode untuk mencapai pertumbuhan berkesinambungan (Lodgaard \& Aslaand, 2011). Program menjalankan program tujuh (7) level yang sudah disusun sebelumnya, kemudian mengevaluasi untuk menemukan solusi dari masalah-masalah yang timbul pada saat implementasi program, sehingga terdapat proses perbaikan yang dapat dijadikan model bagi pengembangan kewirausahaan. Tahapan pelaksanaan pengabdian program Studepreneur STIE Ekuitas disajikan pada Gambar 1.

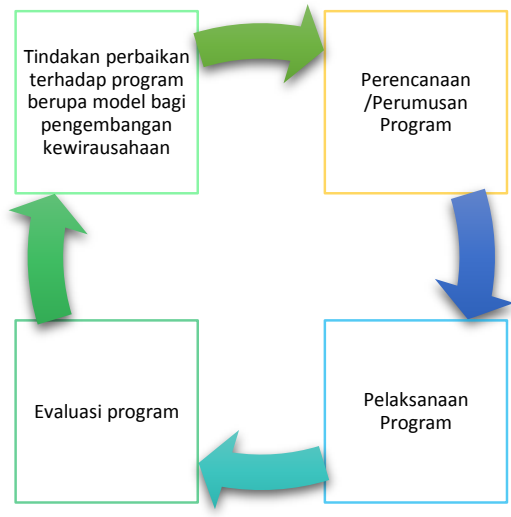

Gambar 1. Tahapan Pelaksanaan Pengabdian 
Keterangan gambar:

1) TIM merumuskan program dan menyusun perencanaan implementasi program

2) Pelaksanaan program 7 level Studepreneur

3) Evaluasi program dengan,dengan melakukan penilaian terhadap implementasi program, serta melakukan survey kondisi peserta studeprenenur setelah mengikuti program.

4) Menyusun model pengembangan kewirausahaan yang efektif, sebagai tindakan perbaikan secara terus-meneur terhadap program yang sudah dijalankan.

Dalam pelaksanaannya program Studepreneur menjalankan 7 level dengan melibatkan berbagai pihak. Berikut 7 level Studepreneur:

Tabel 2. Program Studepreneur

\begin{tabular}{lll}
\hline Level & Aktivitas & Keterangan \\
\hline I & $\begin{array}{l}\text { Pelatihan Kewirausahaan, } \\
\text { Manajemen \& Tutorial }\end{array}$ & Pengelola bekerjasama dengan Kadin \\
\hline II & $\begin{array}{l}\text { Pelatihan } \\
\text { Keterampilan/Magang \& } \\
\text { kunjungan ke perusahaan }\end{array}$ & $\begin{array}{l}\text { Melaukukan kunjungan ke perusahaan dan menerima } \\
\text { pelatihan langsung dari pelaku bisnis, beberapa } \\
\text { tempat yang UMKM yang pernah bekerjasama } \\
\text { diantaranya Ina Cookies, Cantique, BITC dan Bonli } \\
\text { Cipta Sejahtera dalam kegiatan ini juga peserta diberi } \\
\text { kesempatan untuk melakukan magang. }\end{array}$ \\
\hline III & Business Plan \& Tutorial & $\begin{array}{l}\text { Mendapatkan pelatihan penyusunan business plan } \\
\text { dari tim KADIN }\end{array}$ \\
\hline IV & Bursa proposal & $\begin{array}{l}\text { Mendiskusikan hasil business plan yang dibuat } \\
\text { dengan pihak bank dan lembaga keuangan }\end{array}$ \\
\hline V & Kontak bisnis & $\begin{array}{l}\text { Mengadakan pameran produk peserta dan konsultasi } \\
\text { bisnis seperti perizinan, sertifikasi halal, kemasan, dII }\end{array}$ \\
\hline VI & Agenda Bisnis training & Bazar \\
\hline VII & Monitoring, evaluasi dan & $\begin{array}{l}\text { Merupakan aktivitas monitaoring dengan melakukan } \\
\text { kunjungan ketempat usaha anggota untuk memantau } \\
\text { perkembangan usaha anggota studeprenenur }\end{array}$ \\
\hline & konsultasi &
\end{tabular}

Setelah melalui proses seleksi, peserta Studepreneur akan mengikuti pelatihan kewirausahaan, manajemen dan tutorial. Diharapkan melalui pelatihan ini peserta memahami bagaimana bersikap sebagai seorang pengusaha dan mampu mengelola bisnis secara benar. Setelah melalui level 1, peserta kembali mengikuti pelatihan keterampilan yang dibina langsung oleh pelaku wirausaha yang sudah sukses, melalui program ini peserta dapat mendengar langsung dan bertukar pengalaman dengan pelaku usaha yang sudah sukses, sehingga peserta mengetahui 
bagaimana konsep-konsep yang dipelajari di kampus diterapkan pada bisnis sesungguhnya.

Pada level 3 peserta diberi pengetahuan membuat perencanaan bisnis. Berdasarkan pengamatan tim pelaksana pengabdian, peserta Studepreneur tidak membuat perencanaan bisnis (business plan). Kebanyakan mereka menjalankan usaha tanpa menggunakan ilmu pengetahuan.Dengan adanya pelatihan ini mereka dipaksa untuk menyusun business plan.

Pada level 4 peserta mempresentasikan business plan yang mereka buat pada level sebelumnya. Tim pelaksana pengabdian mengundang berbagai pihak yang merupakan ahli dan memahami business plan untuk menilai dan memberi masukan untuk perbaikan proposal bisnis peserta. Pihak-pihak tersebut diantaranya Kadin, Bank dan Akademisi. Peserta secara individu akan mempresentasikan proposal mereka dan akan diberi masukan oleh tim penilai.

Pada level 5 peserta berkonsultasi dengan konsultan-konsultan yang diundang tim pelaksana pengabdian. Konsultan-konsultan tersebut terdiri dari Tim dari BPOM, PIRT, Kadin, Ekspor-Impor, Rumah Kemas, Halal dan Bank. .Pada level 6 peserta akan mengadakan bazar, disini peserta belajar bagaimana memasarkan produk dan memahami apa yang harus dilakukan pada saat bazar, dikarenakan selama ini kebanyakan pelaku usaha ketika mengikuti bazar lebih fokus kepada penjualan unit produk mereka, padahal hal yang lebih penting adalah bazar merupakan ajang promosi.

Setelah semua level dilalui maka akan dilakukan evaluasi, dari hasil evaluasi peserta stupreneur mengalami peningkatan pengetahuan bisnis yang dapat mereka terapkan dalam bisnis mereka. Untuk terus mengetahui kondisi peserta dalam berbisnis setelah mengikuti program, maka para peserta Studepreneur ini dijadikan UMKM binaan STIE Ekuitas. Memasukkan peserta Studepreneur menjadi UMKM binaan, diharapkan komunikasi tidak terputus, selain itu juga peserta berpeluang direkrut oleh Dosen STIE Ekuitas dalam program hibah Dikti. Keuntungan lainnya peserta dapat memasarkan produk mereka melalui gerai kewirausahaan secara online dan offline.

\section{HASIL DAN PEMBAHASAN}

Pengabdian ini menjalankan program inkubator bisnis STIE Ekuitas, sehingga luaran dari pengabdian ini terdiri dari diharapkan mampu membentuk wirausaha-wirausaha yang mandiri, dan selain itu juga pengabdian ini dapat 
menghasilkan model yang tepat bagi pengembangan Kewirausahaan di perguruan tinggi, khususnya di STIE Ekuitas.

Dari hasil pelaksanaan program ditemukan bahwa model terdahulu mengalami permasalahan yaitu setelah selesai program Studepreneur tidak terlihat ada program lanjutan yang mampu memberdayakan dan menjaga kelangsungan dan pengembangan usaha peserta Studepreneur. Berdasarkan permasalahan tersebut maka pada model pengembangan kewirausahaan yang baru, anggota Studepreneur yang sudah menjalankan program sampai dengan tujuh level dijadikan UMKM binaan STIE Ekuitas, dan akan mengikuti program-program pengembangan UMKM yang diadakan STIE Ekuitas, termasuk program gerai, dimana peserta dapat memasarkan barangnya melalui gerai STIE Ekuitas.

Beberapa keuntungan yang diperoleh peserta jika menjadi UMKM binaan STIE Ekuitas diantaranya:

1) Pendampingan UMKM oleh dosen-dosen STIE Ekuitas.

2) Mendapat pengetahuan dan bantuan peralatan-peralatan yang dibutuhkan dalam operasional melalui program pengabdian internal dan hibah Dikti dosendosen STIE Ekuitas.

3) Mendapatkan pelatihan-pelatihan kewirausahaan

132 4) Menerima bantuan modal untuk mengikuti bazar baik yang diadakan STIE Ekuitas ataupun pihak lain.

5) Memperoleh bantuan keuangan untuk peningkatan usaha.

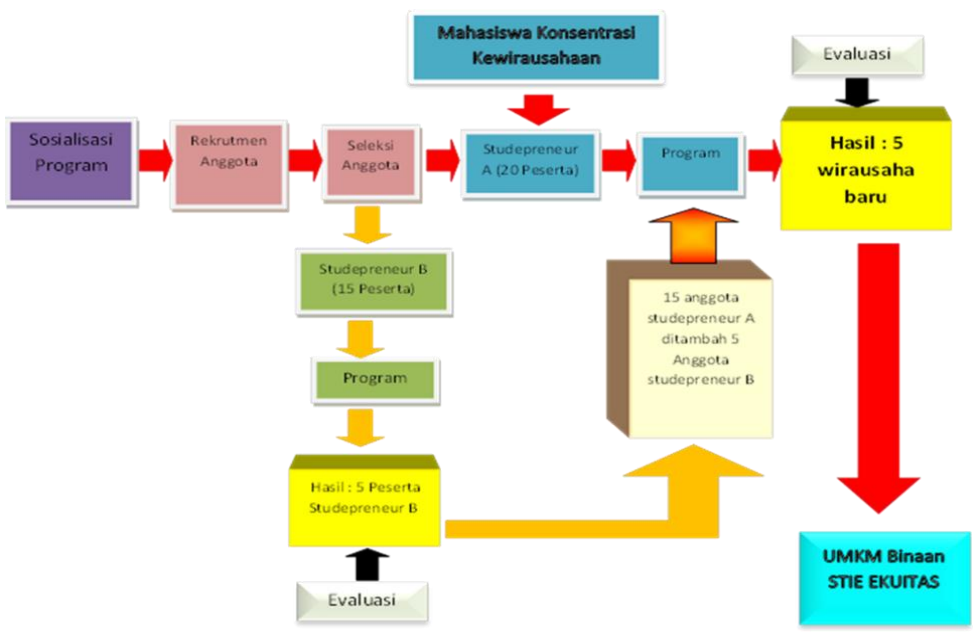

Gambar 2. Model Pengembangan Kewirausahaan STIE Ekuitas

Selain model, luaran dari pengabdian adalah wirausaha baru. Berdasarkan hasil survei dan evaluasi, terdapat 13 peserta (Tabel 3) yang masih aktif menjalankan usahanya, angka ini tentunya jauh diatas target yang ditetapkan 
DIKTI, dimana DIKTI hanya menetapkan 5 (lima) wirausaha baru dalam program IbK. Selain itu juga kemampuan mengelola bisnis peserta juga mengalami peningkatan seperti pengetahuan dalam membuat perencanaan bisnis, pembuatan laporan keuangan, cara mempromosikan barang, dan lain-lain. Dokumentasi kegiatan Studepreneur disajikan pada Gambar 3.

Tabel 3. Data Peserta Studepreneur yang Menjadi Wirausaha Baru

\begin{tabular}{llll}
\hline No & Nama Peserta & Perguruan Tinggi & Bidang Usaha \\
\hline 1 & Indra & ITB & Kosmetik \\
\hline 2 & Shinta & LP3i & Konfeksi \\
\hline 3 & Dalu & LPKIA & Konfeksi \\
\hline 4 & Alvin & STIE Ekuitas & Konfeksi/Perdagangan \\
\hline 5 & Bastiar & STIE Ekuitas & Perdagangan (distributor) \\
\hline 6 & Rizki & STIE Ekuitas & Accessories \\
\hline 7 & Faisal & STIE Ekuitas & Restoran/Kafe \\
\hline 8 & Melinda & STIE Ekuitas & Konfeksi \\
\hline 9 & Nurayyah & STIE Ekuitas & Konfeksi \\
\hline 10 & Risya & STIE Ekuitas & Perdagangan \\
\hline 11 & Vidy & STIE Ekuitas & Perdagangan (distributor) \\
\hline 12 & Fadillah & STIE Ekuitas & Distro \\
\hline 13 & Agya & STIE Ekuitas & Konfeksi \\
\hline
\end{tabular}

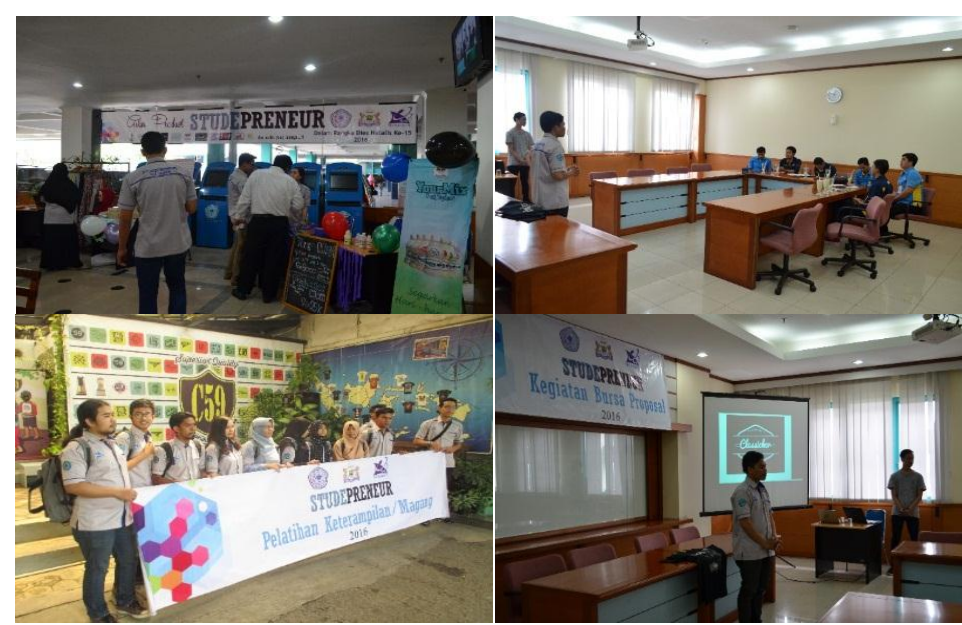

Gambar 3. Foto Dokumentasi Kegiatan Studepreneur

\section{SIMPULAN}

Berdasarkan pelaksanaan pengabdian, dapat disimpulkan bahwa Program Studepreneur berjalan cukup baik, meskipun ditemukan masalah tentang keberlanjutan pembinaan setelah program tujuh (7) level Studepreneur selesai, 
akan tetapi permasalahan tersebut sudah diperbaiki dengan membangun sebuah model pengembangan kewirausahaan yang baru. Perbaikan model tersebut sudah dilakukan dengan menambahkan tahapan, yaitu program UMKM binaan STIE Ekuitas bagi para peserta Studepreneur yang telah mengikuti tujuh level dalam program Studepreneur.

\section{REFERENSI}

Ardiana, I. D. K. R., Brahmayanti, I. A., \& Subaedi, S. (2010). Kompetensi SDM UKM dan pengaruhnya terhadap kinerja UKM di Surabaya. Jurnal Manajemen dan Kewirausahaan, 12(1), 42-55.

Badan Pusat Statistik. (2016). Perkembangan UMKM periode 2007-2013. Jakarta: BPS.

Bank Indonesia. (2015). Profil bisnis usaha mikro, kecil, dan menengah (UMKM). Jakarta: Lembaga Pengembangan Perbankan Indonesia (LPPI).

Hanifah. (2015). The implementation of good corporate governance in efforts to increase profit in small and medium enterprises (SME). International Journal of Business, Economics, and Law, 7(3), 38-46.

Lodgaard, E., \& Aasland, K. E. (2011). An examination of the application of plando-check-act cycle in product development. In S. J. Culley, B. J. Hicks, T. C. McAloone, T. J. Howard, \& A. Dong (Eds.), Design methods and tools part 2. Paper presented at The 18th International Conference on Engineering Design (ICED 11), Technical University of Denmark, Copenhagen, 15-19 August 2011 (pp. 47-55). Copenhagen: The Design Society.

Pinayani, A. (2006). Prospek masa depan kewirausahaan di Indonesia. Jurnal Pendidikan dan Ekonomi Koperasi, 1(1), 1-11.

Suci, Y. R. (2017) Perkembangan UMKM (Usaha mikro kecil dan menengah) di Indonesia. Jurnal Ilmiah Cano Ekonomos, 6(1), 51-58.

\section{Ucapan Terimakasih}

Ucapan terimakasih disampaikan kepada STIE Ekuitas, Kemenristek Dikti, dan Kadin Jawa Barat yang telah mendukung terselenggaranya program pengabdian kepada masyarakat ini. 